\title{
Formulation and Evaluation of Herbal Ultrasound Gel for Ultrasonography
}

\author{
Ferdoushi Jahan", Md. Abdul Momen, Afroza Akter Happy, Md. Hemayet Hossain, \\ Md. Ahedul Akbor, Sharmin Ahmed
}

Bangladesh Council of Scientific and Industrial Research (BCSIR), Dhaka, Bangladesh

Email address:

ferdoushi.bcsir@gmail.com (F. Jahan), mdabdulmomen1994@gmail.com (Md. A. Momen), aahappy025@gmail.com (A. A. Happy), hemayet.hossain02@gmail.com (Md. H. Hossain), akbarbcsir@yahoo.com (Md. A. Akbar), ahmedsharmin62@gmail.com (S. Ahmed)

${ }^{*}$ Corresponding author

\section{To cite this article:}

Ferdoushi Jahan, Md. Abdul Momen, Afroza Akter Happy, Md. Hemayet Hossain, Md. Ahedul Akbor, Sharmin Ahmed. Formulation and Evaluation of Herbal Ultrasound Gel for Ultrasonography. Journal of Diseases and Medicinal Plants. Vol. 6, No. 1, 2020, pp. 11-15. doi: 10.11648/j.jdmp.20200601.12

Received: December 12, 2019; Accepted: January 2, 2020; Published: January 21, 2020

\begin{abstract}
This research paper provides the formulation idea of herbal ultrasound gel that is of good quality. In this formulation some available chemicals and natural ingredient were used which has no harmful effect to human skin. Chemicals that used were poly acrylic acid, sodium benzoate, glycerine, food grade color, tri-ethanolamine and natural ingredient is aloe vera extract which shows effective activity against allergic, irritation and inflammation problem due to its synergistic property. Firstly, aloe gel was extracted by ethanol extraction. Gel was formulated combining all ingredients. To justify the effectiveness of any formulation, results of evaluation tests are very important. For this, necessary physicochemical properties such as appearance, transparency, consistency, homogeneity, $\mathrm{pH}$, thermal stability, conductivity, spreadability, viscosity etc. were evaluated. The results were satisfactory. No microbial growth was found during the incubation period for the prepared ultrasound gel. Also, no adverse effect to the human skin like irritation, allergy, inflammation etc. was observed. Ultrasound gel usually acts as a conductive medium and the conductivity result provides the information about the image quality. Conductivity of this formulated gel was $4.05 \mu \mathrm{S} / \mathrm{cm}$. Using this formulated ultrasound gel during ultrasonography, clear image was found which was also of good quality. The overall results suggest that this formulation can be considered as successful and used with no harmful effect compared to the synthetic ones.
\end{abstract}

Keywords: Ultrasonography, Poly Acrylic Acid, Aloe Vera Extract, Ultrasound Gel

\section{Introduction}

Ultrasound is widely used in rehabilitation, primarily for improving connective tissue extensibility and for promoting tissue healing and remodelling. The level of clinical benefit from therapeutic ultrasound remains uncertain, and depends on the application. Risk of harm is considered low when used properly, making ultrasound for physical therapy a treatment of modest efficacy but low risk. Topical analgesics will activate superficial thermal response receptor, providing hot or cold sensation. Topical herbal extracts suspended in aqueous gel are more effective in transmitting ultrasound energy, compared to cream-based agents which are less effective [1-3].
Diagnostic ultrasound utilizes high-frequency sound waves to produce images of body internal organs and soft tissues. But sound waves cannot travel very well through air, that's why ultrasound gel is required. This gel serves as conductive medium that covers tiny pockets of air in the skin, enabling a tight bond between the skin and the transducer, letting the waves transmit directly to the tissues beneath and to the parts that image to be needed. Ultrasound gel is a medicine gel. It is used frequently in most hospitals, clinics and therapist centres. It helps to avoid intense sound reflections caused by air pockets at the borderline between the ultrasonic probe and skin. The best ultrasonic media is free of air bubbles to ensure perfect sound transmission [4-5].

It is formulated in such a way that gel can act as a coupling agent and reduce static. The ultrasound waves have a hard 
time travelling through air, so the gel prevents any extra air space between the probe and human skin in order to create a clear image of the fetus [6].

In recent years, ultrasound gel has become commonly used as a conductive medium in many diagnostic procedures such as electrocardiography, ultrasonography, endoscopy, and transesophageal echocardiogram examinations [7].

Unfortunately, some chemicals are being used for the preparation of ultrasound gel those are allergenic to skin, such as phenoxyethanol, methylisothiazolinone and isothiazolinones which are used as preservatives for many industrial and cosmetics products and there are many publications dealing with patients who have developed allergic dermatitis as a result of using these chemicals in the formulation of the gel [8-10]. Moreover, women, in particular, may develop sudden allergic reactions to these above stated chemicals during pregnancy, which is often a result of the massive hormonal changes they go through. Aloe vera has anti-inflammatory action, anti oxidant, antiageing action, antimicrobial, antifungal properties and promote wound healing. Aloe vera shows synergistic effects because it has 75 active components [11] which provide special activities to healing allergic dermatitis, cancer, skin diseases, liver problems and AIDS [12-13]. Specialized gels for ultrasound are prepared using aloe vera which does not contain impure additives that may irritate the skin. Hence, they will be generally safer and better for people with skin sensitivity issue.

\section{Materials \& Methods}

\subsection{Materials}

The chemicals required for the formulation of ultrasound gel are:

a) Poly acrylic acid.

b) Sodium benzoate.

c) Glycerine.

d) Food grade colour.

e) Tri-ethanolamine.

These were purchased from the local market.

The natural ingredient required for the formulation of ultrasound gel is aloe vera plant which was collected also from local market.

\subsection{Methods}

\subsubsection{Preparation of Aloe Vera Extract}

At first, aloe vera leaves were washed carefully with tape water. The epidermis of the washed aloe vera leaves was peeled off and the parenchymatous tissue was collected. The colourless, solid mucilaginous gel was cut into small pieces. The gel was lyophilized and ground. The lyophilized gel powder was then packed into Soxhlet apparatus and extracted with $90 \%$ ethanol at $90^{\circ} \mathrm{C}$ for $4 \mathrm{hrs}$. The ethanol containing the extract was filtered and concentrated using rotary evaporator and preserved in a refrigerator.

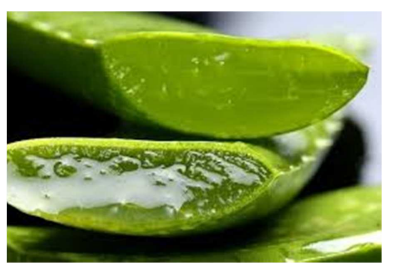

Figure 1. Aloe Vera leaves.

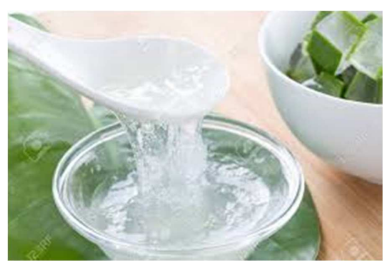

Figure 2. Aloe Vera gel.

\subsubsection{Ultrasound Gel Formulation}

First of all, poly acrylic acid was dispersed in distilled water with continuous stirring using mechanical stirrer. Secondly, required quantity of sodium benzoate was dissolved in distilled water and heated on water bath to dissolve properly. This solution was cooled and then glycerine and aloe vera extract were added and finally mixed with firstly prepared solution. Then required quantity of food grade colour was added to the above mixture and volume was made up using remaining distilled water. Finally, triethanolamine was added drop wise to the formulation for adjustment of required $\mathrm{pH}$ and to obtain gel in required consistency [14]. Figure 3 shows the prepared ultrasound gel and table 1 shows its composition.

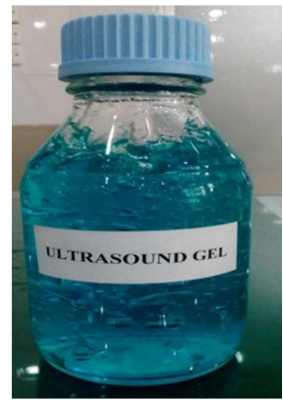

Figure 3. Formulated ultrasound gel.

Table 1. Composition of ultrasound gel.

\begin{tabular}{lll}
\hline SL. No. & Ingredients & Quantity (\%) \\
\hline 1. & Polyacrylic acid $(\mathrm{g})$ & 0.5 \\
2. & Triethanolamine $(\mathrm{mL})$ & 3 \\
3. & Glycerine $(\mathrm{mL})$ & 3 \\
4. & Aloe vera extract $(\mathrm{mL})$ & 2 \\
5. & Sodium benzoate $(\mathrm{g})$ & 0.1 \\
6. & Color $($ Food grade) $(\mathrm{g})$ & 0.1 \\
7. & Water $(\mathrm{mL})$ & 91.3 \\
\hline
\end{tabular}

\section{Evaluation of Prepared Ultrasound Gel}

The following parameters were used to evaluate the formulated gel: 


\subsection{Visual Clarity and Appearance}

Prepared gel formulation was inspected visually for its clarity, appearance, colour, and consistency against a black and white background [15-16].

\subsection{Transparency}

Approximately $5 \mathrm{~mL}$ of formulated gel was taken in the 10 $\mathrm{mL}$ test tube and its transparency was checked visually.

\subsection{Homogeneity}

The formulation was tested for the homogeneity by visual appearance and by touch.

\section{4. $\mathrm{pH}$}

The $\mathrm{pH}$ meter was calibrated using standard buffer solution. About $0.5 \mathrm{~g}$ of the gel was weighed and dissolved in $50.0 \mathrm{~mL}$ of distilled water and its $\mathrm{pH}$ was measured.

\subsection{Thermal Stability}

With the help of a spatula, the gel was inserted into a glass bottle and tapped to settle at the bottom. Two-third of the bottle was filled up and plug was inserted into it and then the cap was tightened. This filled bottle was kept erect inside the incubator at $45^{\circ} \mathrm{C}$ for 48 hours [17].

\subsection{Removal}

The ease of removal of the gel applied was examined by rubbing the applied part with tissue paper.

\subsection{Non-Volatile Matter}

Approximately 1-5 gm of the prepared gel was weighed in a tred evaporating dish and heated on a steam-bath until most of the volatile matter had escaped. Heating was continued at $105^{\circ} \mathrm{C}$ in an oven for 2 hours. Then it was cooled in a desiccator and the weight was taken. The procedure of heating, cooling and weighing were repeated until the difference in mass between two successive weights did not exceed $1 \mathrm{mg}$.

The formula for calculation is

$$
\text { Non-Volatile Matter }=\left(m_{2}-m_{3}\right) \times 100 /\left(m_{1}-m_{3}\right)
$$

Where,

$\mathrm{m}_{1}=$ mass, in grams, of the dish with the sample.

$\mathrm{m}_{2}=$ mass, in grams, of the dish after heating and.

$\mathrm{m}_{3}=$ mass, in grams, of the empty dish.

Spreadability Test

Sample was applied between two glass slides and then compressed to uniform thickness by placing $100 \mathrm{gm}$ weight for 5 minutes. Weight was added to the pan. The time required to separate the two slides i.e. the time in which the upper glass slide moved over the lower slide was taken as measure of spreadability. [18]

The formula is

\section{Spreadability $=\mathrm{ml} / \mathrm{t}$}

Where,

$\mathrm{m}=$ Weight tide to upper slide.

$\mathrm{l}=$ length moved on the glass slide.

$\mathrm{t}=$ time taken.

Viscosity

Brookfield viscometer was used to measure the viscosity and torque of the formulated gel in addition to the $\mathrm{CG}$ at $23 \pm 2{ }^{\circ} \mathrm{C}$ using spindle (T-Bar, TD-94). Sample holder of the Brookfield viscometer was filled with the gel sample and then spindle was inserted into this holder. The spindle was rotated at $20 \mathrm{rpm}$. Viscosity and Torque measurements were recorded in triplicate [19-20].

Skin Irritation Test

Skin irritation test was performed for the prepared ultrasound gel by applying it on human volunteers to find out any irritation problems which could make it unsuitable for use. Three human volunteers were selected to check skin irritancy test. 1 gm of the sample was topically applied to the hand over a 2 square inch. In this test, the three human volunteers signed an informed consent letter for their agreement to participate. Observation for any lesions, irritation, edema or redness was performed at regular intervals for about $24 \mathrm{hrs}$ and recorded [20-21].

\section{Accelerated Stability Test}

Accelerated stability test of prepared gel was conducted for stable formulation at room temperature, studied for 7 days. This formulation was studied at $40^{\circ} \mathrm{C} \pm 1{ }^{\circ} \mathrm{C}$ for 20 days. The formulation was kept both at room and elevated temperature and observed on 0th, 5th, 10th, 15th and 20th day with required parameters [22-26].

Microbial Growth Test

The formulated gel was inoculated on the plates of agar media by streak plate method and a control was prepared by omitting the gel. The plates were placed inside the incubator and kept at $37^{\circ} \mathrm{C}$ for 24 hours. After the incubation period, plates were taken out and the microbial growth was checked by comparing it with the control [27].

\section{Conductivity}

The conductivity of the formulated ultrasound gel was measured by using $\mathrm{HACH}$ conductivity meter (Model: sension $^{\mathrm{TM}} 156$ portable multi parameter). This measuring system has a two-cell probe design. With this design, a single probe can take measurement within the full, dynamic range of the instrument. This method determines the total conductivity. Before going to analysis sample, the meter was calibrated. Then the probe was placed into the sample and the slot on the end of the probe was totally immersed. The sample was agitated with the probe for 5-10 seconds to remove bubbles that might be trapped in the slot. The conductivity value of the sample was then automatically displayed on the instrument.

Image Quality

The image quality was visually inspected. 


\section{Results \& Discussions}

\section{Visual Clarity and Appearance}

Clarity is one of the most important characteristic features of ultrasound gels. This formulation was of high clarity, transparent, with blue colour, smooth homogeneous texture, and glossy appearance.

Transparency

The formulated gel was transparent.

Homogeneity

The formulation was tested for the homogeneity by visual appearance and by touch, result showed appearance and touch was good and non greasy.

pH of the Gel

The $\mathrm{pH}$ of the gel was found to be 6.8 which is good for skin.

\section{Thermal Stability Test}

The formulation was passed the test.

Removal

The gel applied on skin was easily removed by rubbing with tissue paper.

Non volatile Matter

The formulation was shown $10 \%$ non volatile Matter.

Spreadability Test

The spreadability test showed that formulation has good spreadable property.

Viscosity

The viscosity of gel was very good which indicates that the gel is easily spreadable by small amounts of shear. The formulation was shown viscosity $35652 \mathrm{cp}$.

Skin Irritation Test

The formulation shows no redness, oedema, inflammation and irritation during irritancy studies. This formulation is safe to use for skin.

Accelerated Stability Testing

The formulation was kept both at room and elevated temperature and observed on 0th, 5th, 10th, 15th and 20th day for the all evaluation parameters. The stability results showed that the formulation was good.

Microbial Growth Test

There were no signs of microbial growth after incubation period of 24 hours at $37^{\circ} \mathrm{C}$ for the sample gel compared with the control.

\section{Conductivity Test}

The formulation was shown conductivity of $4.05 \mu \mathrm{S} / \mathrm{cm}$ Image Quality

The formulated ultrasound transmission gel was applied to a pregnant woman for ultrasonography and hence a clear and good quality image of the fetus was obtained from the ultrasonogram (Figure 4). This proved that the gel was acceptable for ultrasonography as no other problem was arrived.

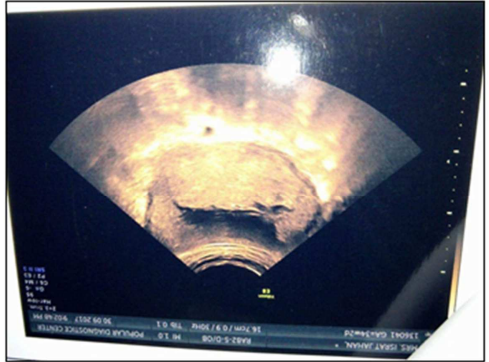

(a)

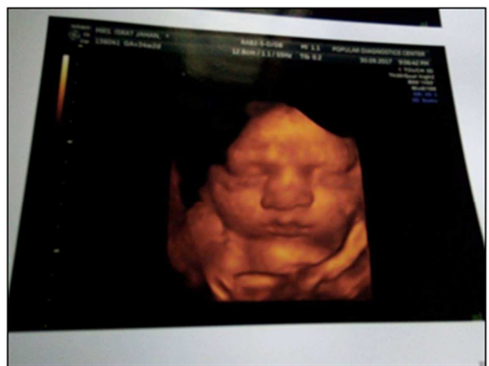

(b)

Figure 4. (a) and (b) both are the images of the fetus found from the ultrasonogram by using the formulated ultrasound gel.

All the results obtained from the evaluation of the prepared ultrasound gel are listed at table 2 .

Table 2. Physicochemical properties of the formulated ultrasound gel.

\begin{tabular}{lll}
\hline S. L. NO. & Parameter & Result \\
\hline 1. & Visual clarity and appearance & Good \\
2. & Transparency & Clear \\
3. & Homogeneity & Good \\
4. & pH & 6.8 \\
5. & Thermal Stability & To pass the test \\
6. & Removal & Easy \\
7. & Non-Volatile Matter & $10 \%$ \\
8. & Spreadability test & Good \\
9. & Viscosity & $35652 \mathrm{cp}$ \\
10. & Skin irritation Test & Safe for use \\
11. & Accelerated stability test & Stable \\
12. & Microbial growth test & Nil \\
13. & Conductivity & $4.05 \mu \mathrm{S} / \mathrm{cm}$ \\
14. & Image quality & Clear and good \\
\hline
\end{tabular}

\section{Conclusion}

Pure aloe vera extract has an anti-inflammatory effect on the skin. This extract is obtained from the aloe vera plant which is well-known for its healing power since centuries. It provides improved conductivity; hence the formulated ultrasound gel using it creates an optimal contact between the device and the skin. Aloe vera is cheaper and widely available too. Gentle formulation with it is perfect for patients with sensitive skin due to its hypoallergenic properties.

The overall results suggest that the formulation can be considered a successful herbal ultrasound gel which is cheap and good compared to synthetic ones. The prepared formulation showed good spreadability, no evidence of phase separation and good consistency during the study 
period. Stability parameters like visual appearance, nature, viscosity of the formulation showed that there was no significant variation during the study period. The prepared formulation showed proper $\mathrm{pH}$ 6.8; it confirms the compatibility of the formulation with skin secretions. The gel was found to be stable during stability study. From the present study it can be concluded that the formulated herbal ultrasound gel can be used to take medical images during ultrasound scan.

\section{References}

[1] Anderson MB, Eggett D. Combining topical analgesics and ultrasound - Part 2. Athletic Therapy Today. 2005, 10, 45-47.

[2] Cage SA, Rupp KA, Castel JC, Saliba EN, Hertel J, Saliba SA. Relative acoustic transmission of topical preparations used with therapeutic ultrasound. Archives of physical medicine and rehabilitation. 2013, 94, 2126-2130.

[3] Draper DO, Anderson MB. Combining topical analgesics and ultrasound - Part 1. Athletic Therapy Today. 2005, 10, 26-27.

[4] https://aurorapharmaceutical.com/wpcontent/uploads/2012/10/Clarity-Ultrasound-Gel-v2-6-25-12.pdf.

[5] http://how2make.in/index.php?main_page=product_info\&pro ducts_id $=2500$.

[6] http://www.premierus.com/blog/news/post/ultrasound-gelwhat-it-is-and-why-we-need-it.

[7] Lutz H, Buscarini E and Mirk P. Basic Physics. WHO Manual of Diagnostic Ultrasound. 2nd ed. V-2, Geneva, Switzerland: World Health Organization Press; 2011, 3-4.

[8] Binkowski A, Riguzzi C, Price D, Fahimi J. Evaluation of a cornstarch-based ultrasound gel alternative for low-resource settings. J. Emerg. Med. 2014, 47, e5-9.

[9] Garcia-Miguel J, Lamas-Doménech N, Barceló-Garcia P. Allergic contact dermatitis in medical professionals due to exposure to ultrasound gel. Reumatol Clin. 2016, 12, 115-116.

[10] Chasset F, Soria A, Moguelet P, Mathian A, Auger Y, Francès C. Contact dermatitis due to ultrasound gel: A case report and published work review. J. Dermatol. 2016, 43, 318-320.

[11] Mahendran Sekar, Afikaah Sha An Ali, Ganesh Sundaram Subramanian, Vengata Subramani Manoharan, Isaac Jason J, Phan Ai Yean. Formulation and evaluation of natural ultrasound gel for physiotherapy treatment, Indo American Journal of Pharmaceutical Science, 2017, 4, 2548-2554.

[12] Egesie UG, Chima KE, Galam NZ. Antiinflammatory and analgesic effects of aqueous extract of Aloe vera (Aloe barbadensis) in rats. African Journal of Biomedical Research 2011, 14, 209-212.

[13] Asim Kumar G, Manasi B, Tapan Kumar M, Akhilesh M,
Mrinal Kanti B. A study on analgesic efficacy and adverse effects of Aloe vera in wistar rats. Pharmacology online 2011, $1,1098-1108$.

[14] Dwivedi S, Gupta S. Formulation and evaluation of herbal gel containing Sesbania grandiflora (L) poir leaf extract. Acta Chim Pharm Indica. 2012, 2, 54-59.

[15] Patil S, Kadam A, Bandgar S. Formulation and evaluation of an in situ gel for ocular drug delivery of anti conjunctival drug. Cellulose Chem. Technol. 2015, 49, 35-40.

[16] Prasanthi D, Lakshmi PK. Optimisation of transdermal gel formulations of tolterodine tartrate by experimental design. Turk J Pharm Sci 2013, 10, 273-86.

[17] Bangladesh standard Specification for skin creams, BDS 1382: 2015.

[18] S. K. Sahoo, A. R. Samal, A. A. Mallick, S. Patra, P. C. Senapati and B. B. Barrick, Estimation and evaluation of secnidazole. The Indian Pharmacist, 2006, 5, 73-76.

[19] Helal DA, El-Rhman DA, Abdel-Halim SA, El Nabarawi MA. Formulation and evaluation of fluconazole topicl gel. Int $J$ Pharm Pharm Sci. 2012, 4, 176-183.

[20] Shukr MH, Metwally GF. Evaluation of topical gel bases formulated with various essential oils for antibacterial activity against methicillinresistant Staphylococcus aureus. Trop. J Pharm Res. 2013, 12, 877-884.

[21] Khullar R, Kumar D, Seth N, Saini S. Formulation and evaluation of mefenamic acid emulgel for topical delivery. Saudi Pharm J. 2012, 20, 63-67.

[22] Sahu AN, Jha SB, Dubey SD. Formulation \& Evaluation of Curcuminoid Based Herbal Face Cream. Indo-Global Journal of Pharmaceutical Sciences. 2011, 1, 77-84.

[23] Vinod KR, Santhosha D, Anbazhagan S. Formulation and evaluation of piperine creama new herbal dimensional approach for vitiligo patients. Int J Pharm Pharm Sci. 2011; 3, 29-33.

[24] Jagtap NS, Khadabadi SS, Farooqui IA, Nalamwar VP, Sawarkar HA. Development and evaluation of herbal wound healing formulations. Int. J. PharmTech Res. 2009, 1, 1104-1108.

[25] Grimm W. Extension of The International Conference on Harmonization Tripartite Guideline for Stability Testing of New Drug Substances and Products to Countries of Climatic Zones III and IV. Drug Development and Industrial Pharmacy. 1998, 24, 313- 325.

[26] Forster T, Rybinski WV, Wadle A. Influence of Microemulsion Phases on The Preparation Of Fine Disperse Emulsions. Adv. In Colloid \& Interface Sci. 1995, 58, 119149.

[27] N. MarieLode, I. Buraczewska, K. Halvarsson, Facial antiwrinkle cream: influence of product presentation on effectiveness: a randomized and controlled study. Skin Res Technol. 2007, 13, 189-194. 